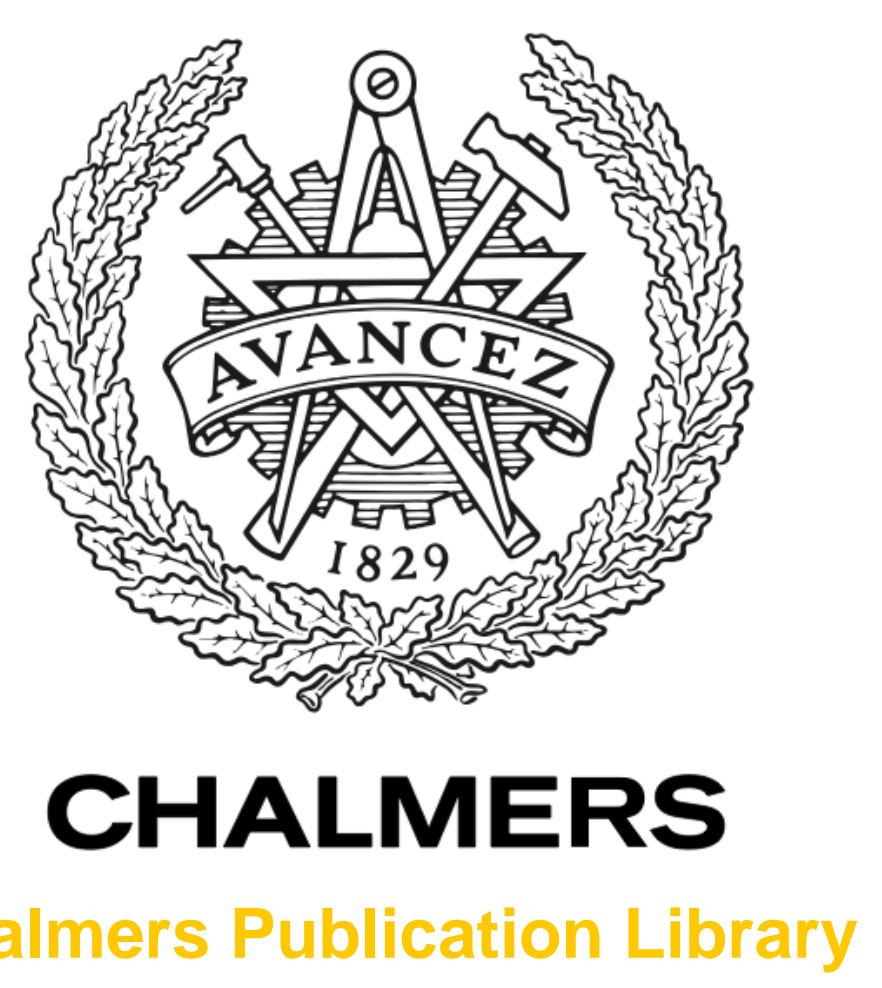

Chalmers Publication Library

\title{
Effect of ethanol on the water permeability of controlled release films composed of ethyl cellulose and hydroxypropyl cellulose
}

This document has been downloaded from Chalmers Publication Library (CPL). It is the author's version of a work that was accepted for publication in:

European Journal of Pharmaceutics and Biopharmaceutics (ISSN: 0939-6411)

Citation for the published paper:

Larsson, M. ; Hjärtstam, J. ; Berndtsson, J. et al. (2010) "Effect of ethanol on the water permeability of controlled release films composed of ethyl cellulose and hydroxypropyl cellulose". European Journal of Pharmaceutics and Biopharmaceutics, vol. 76(3), pp. 428432.

http://dx.doi.org/10.1016/j.ejpb.2010.09.007

Downloaded from: http://publications.lib.chalmers.se/publication/130297

Notice: Changes introduced as a result of publishing processes such as copy-editing and formatting may not be reflected in this document. For a definitive version of this work, please refer to the published source. Please note that access to the published version might require a subscription.

Chalmers Publication Library (CPL) offers the possibility of retrieving research publications produced at Chalmers University of Technology. It covers all types of publications: articles, dissertations, licentiate theses, masters theses, conference papers, reports etc. Since 2006 it is the official tool for Chalmers official publication statistics. To ensure that Chalmers research results are disseminated as widely as possible, an Open Access Policy has been adopted.

The CPL service is administrated and maintained by Chalmers Library. 
2 Effect of ethanol on water permeability of controlled release films composed of ethyl

3 cellulose and hydroxypropyl cellulose

4

5 Mikael Larsson ${ }^{a^{*}}$, Johan Hjärtstam ${ }^{\text {b }}$, Jolina Berndtsson ${ }^{\text {b }}$, Mats Stading ${ }^{\mathrm{c}}$, d, and 6 Anette Larsson ${ }^{a}$

7

8 a Department of Chemical and Biological Engineering, Chalmers University of Technology,

941296 Göteborg, Sweden.

10 b AstraZeneca R\&D Mölndal, SE-43183 Mölndal, Sweden

11 c Department of Materials and Manufacturing technology, Chalmers University of 12 Technology, 41296 Göteborg, Sweden.

13 d Structure and Material Design, SIK - The Swedish Institute for Food and Biotechnology, 14 PO Box 5401, 40229 Göteborg, Sweden

\section{${ }^{*}$ Corresponding author}

E-mail: mikael.larsson@chalmers.se 
28 Films for controlled release, composed of ethyl cellulose and hydroxypropyl cellulose were prepared in various compositions and the effect of ethanol in the dissolution medium on the water permeability of the films was studied using a modified Ussing chamber and tritiated water. It was found that the effect of ethanol on the film permeability varied depending on the composition of the films. The results were interpreted in terms of swelling of the ethyl cellulose in the films, where the swelling increased with increasing ethanol concentration. Thus, for films with low HPC content (non interconnected pores) the water permeability of the films increased with increasing ethanol concentration as the diffusion through the ethyl cellulose increased due to swelling. However, for films with higher HPC content (having interconnected pores through the films) the permeability decreased, likely due to the swelling of the ethyl cellulose blocking the pores. The interpretation of the results was supported by dynamic mechanic analysis and SEM analysis.

40

Keywords: Ethyl cellulose, Hydroxypropyl cellulose, Permeability, Films, Controlled release 


\section{Introduction}

Polymer film coatings are commonly used for controlling drug release from pellets and tablets (Shah and Sheth, 1972; Donbrow and Samuelov, 1980; Sakellariou and Rowe, 1995; Hyppoelae et al., 1996; Hjartstam and Hjertberg, 1999; Marucci et al., 2009;). In order to modify the release, different ratios of water insoluble film forming polymer and water soluble pore forming agent are used. Ethyl cellulose (EC) is a commonly used film forming agent (Hyppoelae et al., 1996) because it has good film forming properties and is generally regarded as non-toxic and non-allergenic (Hjartstam and Hjertberg, 1998; Marucci et al., 2009). Water soluble cellulose derivates, such as hydroxypropyl cellulose (HPC) and hydroxypropyl methylcellulose (HPMC) are commonly used as pore forming agents in controlled release films (Sakellariou and Rowe, 1995; Hjartstam and Hjertberg, 1998; Marucci et al., 2009). HPC has low toxicity, is biodegradable and has good film forming properties (Marucci et al., 2009). Furthermore, HPC holds a great benefit over HPMC in industrial film spraying processes. HPC can be co-dissolved with EC in ethanol, while HPMC requires the use of other more hazardous solvents. Films composed of EC and HPC have been studied both with regard to structure and permeability. It has been shown that EC and HPC phase separate in the films (Sakellariou et al., 1986, 1988) and that the permeability of the films and the release rate from formulations increases with increasing HPC content (Thombre et al., 1994; Marucci et al., 2009). Furthermore, the permeability of the films as well as the release of the pore forming HPC has been shown to be low below a critical HPC content, this being explained by that at low HPC concentrations the pore forming network is not interconnected through the film ( Sakellariou et al., 1988; Marucci et al., 2009).

Recently, regulatory authorities have expressed concerns over the effects of alcohol on extended release dosage (ER) forms, with potential dose dumping as a consequence (FDA, 
2005; Meyer and Hussain, 2005). A regulatory framework regarding the effects of ethanol on product performance and classification is currently being developed (Meyer and Hussain, 2005). Levina et al. (2007) have investigated the influence of ethanol on drug release from HPMC based ER matrices, and reported that none of the investigated formulations exhibited dose dumping when exposed to hydro-alcoholic solutions. However, Fadda et al. (2008) investigated the influence of ethanol in the dissolution media on modified release tablets coated with enteric methacrylic acid and methyl methacrylate ester copolymer. They found that the influence of ethanol on the drug release was complicated, and concluded that several tests are needed before making a decision on a formulations susceptibility to ethanol impairment. Given the recent interest in the effect of ethanol on controlled release formulations and the fact that EC (ETHOCEL ${ }^{\mathrm{TM}}$ ) is soluble in alcohol (Dow Cellulosics, 2005), it was considered interesting to investigate the effects of hydro-alcoholic solutions on EC-HPC films for controlled delivery.

The aim of this study was to evaluate how the water permeability of EC films with varying HPC content was affected by the presence of ethanol in the dissolution medium, and explain the mechanism by which the permeability was affected. The water permeability of the films was determined using a modified Ussing chamber, utilizing tritiated water as the diffusing probe. Swelling of the films and changes in mechanical properties upon exposure to ethanol solutions were studied using dynamic mechanic analysis (DMA). Finally, the structure of films exposed to ethanol solutions and subsequently dried was studied using scanning electron microscopy (SEM).

\section{Materials and methods}

\subsection{Materials}


91 The films in this study were prepared from ethyl cellulose (ETHOCEL ${ }^{\mathrm{TM}}$ 10, Dow Chemical, 92 USA) and hydroxypropyl cellulose (HPC LF, Ashland, USA). Ethanol used was of $95 \%$ v/v concentration (Kemetyl AB, Sweden), water used was ultra-pure deionized (Maxima USF, Elga, UK). Tritiated water (PerkinElmer, USA) was used as the diffusant in the water permeability measurements.

\subsection{Film preparation}

Films of EC with varying amount of $\operatorname{HPC}(0,20,30,35,40,50 \% \mathrm{w} / \mathrm{w})$ were prepared as follows. Desired amounts of EC and HPC were dissolved in ethanol $(95 \% \mathrm{v} / \mathrm{v})$ to a total polymer content of $6 \% \mathrm{w} / \mathrm{w}$. The solution was sprayed, using a moving nozzle (Schlick 9700, nozzle diameter $0.8 \mathrm{~mm}$, Schlick, Germany), onto a rotating Teflon cylinder (In-house manufactured, length $100 \mathrm{~mm}$ diameter $65 \mathrm{~mm}$ ) in a controlled air flow. The process conditions are presented in Table 1. The dry film was peeled off the cylinder and cut into suitable geometries for permeability and DMA analysis. The thicknesses of the films were 70$90 \mu \mathrm{m}$ as measured with a micrometer (IP 54, Mitutoyo, Japan).

\subsection{Water permeability analysis}

The water permeability of the films was analyzed using a modified Ussing chamber with the setup previously described (Hjartstam and Hjertberg, 1999). Briefly, a film sample was placed between a donor and acceptor compartment. The film thickness was determined as the average of five measurements. Initially $15 \mathrm{ml}$ of dissolution medium with $0,5,20$ or $40 \% \mathrm{v} / \mathrm{v}$ ethanol concentration was added to both the donor and the acceptor compartments and two paddles were used to stir the dissolution medium at a speed of $200 \mathrm{rpm}$. After 5 minutes a 
114 small amount of tritiated water $(10 \mu \mathrm{l}, 400 \mathrm{kBq})$ was added to the donor compartment. At

115 specified times $500 \mu \mathrm{l}$ sample was taken from the acceptor compartment and was replaced by

116 the same amount of dissolution medium. The temperature was maintained at $37{ }^{\circ} \mathrm{C}$ through

117 the analysis. The samples extracted at the different times were weighed and analyzed in a

118 scintillator counter (1414 LSC, Win Spectral, Wallac). From the tritium activity registered in

119 the acceptor compartment at the different times, the amount of water that had diffused

120 through the film at each time could be determined, and thus the film permeability. Due to the

121 large difference in tritium activity between the donor and acceptor compartment any counter

122 diffusion was neglected.

\subsection{Dynamic mechanic analysis}

125 DMA measurements were performed using a Rheometrics RSAII (Rheometrics Scientific,

126 Piscataway, USA), equipped with an in house designed submersion cell (Edrud et al., 2003).

127 Samples were prepared to a width of $3 \mathrm{~mm}$ using a razor-edged punch. The sample thickness

128 was recorded as the average of three measurements. The effective initial sample length in the

129 DMA was 22-23 mm. The samples were mounted in the DMA and after about 3 minutes 40

$130 \mathrm{ml}$ of dissolution medium with $0,5,20$ or $40 \% \mathrm{v} / \mathrm{v}$ ethanol concentration was added.

131 The samples were analyzed in strain controlled stretching mode with a static force, keeping

132 the samples stretched, set to just exceed the amplitude of the harmonic dynamic force. The

133 deformation and the force response of the samples were monitored and from those parameters

134 the elastic modulus $G^{\prime}$ and the loss factor, $\tan (\delta)$, were calculated. Equilibrium value of $\tan (\delta)$

135 was taken as the average of the plateau values. The swelling of the samples was monitored as

136 the percent length change. 
139 Free polymer films with varying EC and HPC content were placed in beakers with dissolution

140 media containing 0, 5, 20 and $40 \%$ ethanol for two days. The films were subsequently dried

141 and analysed using a scanning electron microscope (Quanta200, FEI, Czech Republic).

\section{3. Results and discussion}

\subsection{Water permeability analysis}

145 In order to investigate the influence of ethanol in the dissolution medium on water

146 permeability of EC-HPC films for controlled drug delivery, film samples were subjected to

147 permeability analysis. The analyses were conducted in dissolution media with different

148 ethanol concentrations using a modified Ussing chamber. The film samples were placed

149 separating the two compartments of the cell, and from the transport of tritiated water from the

150 donor to the acceptor compartment the volume of water that had diffused across the

151 membrane was calculated at each time. As seen in the exemplifying graph in Fig. 1, the

152 volume of water that had diffused across the membrane showed a linear dependence on time.

153 From the slope of the graphs the volume flow was calculated and the water permeability,

154 normalized versus film thickness, was determined as:

$155 \quad P_{N}=\frac{J \cdot h}{A}$

156 where $P_{N}$ is the water permeability, $J$ is the volume flow, $h$ is the film thickness and $A$ is the 157 area. 
158 The permeability data (see Table 2 and Fig. 2) revealed that, in general, the water

159 permeability of the films increased with increasing HPC content. This is expected as HPC is 160 widely soluble both in water and in ethanol (Rowe et al., 2009), and thus should dissolve and

161 leave pores. Furthermore, the permeability was very low up to $20 \%$ HPC content. This is in 162 agreement with a previous study on the permeability of EC-HPC films in non-ethanol 163 containing dissolution media (Marucci et al., 2009). For samples analyzed in the presence of $16440 \% \mathrm{v} / \mathrm{v}$ ethanol in the dissolution medium, some deviations from the trend were seen. If instead looking at the permeability for a fixed HPC content and varying ethanol concentration in the dissolution media, the permeability of films with low HPC contents ( 0 and $20 \% \mathrm{w} / \mathrm{w})$

167 increases with increasing ethanol concentrations. However, at HPC contents higher than $20 \%$ $168 \mathrm{w} / \mathrm{w}$ the permeability instead decreases with increasing concentration of ethanol in the 169 dissolution medium. Only one exception from the trend is seen, the permeability of the samples with $30 \%$ w/w HPC in $5 \%$ v/v ethanol is higher than suggested by the trend.

171 We propose the following explanation for the changes in film permeability in ethanol 172 containing dissolution medium. At low HPC concentrations the dissolution of HPC will not 173 form a coherent pore network though the film, in accordance with previous studies ( 174 Sakellariou et al., 1988; Marucci et al., 2009). Thus, the permeability of the films will be low.

175 Ethyl cellulose is however soluble in ethanol. It would be expected that upon increasing the 176 ethanol content in the dissolution medium, the solubility of EC is increased, with gelling and 177 in the extreme dissolution as a consequence. It is well known that the diffusion coefficient in 178 polymeric materials increases with decreasing polymer concentration (Masaro and Zhu, 179 1999). Thus, due to the swelling of the EC, the permeability of films with low HPC content is 180 expected to increase with increasing ethanol concentration in the dissolution medium. For 181 films with higher HPC content, the dissolution of HPC will lead to the formation of a 182 coherent pore network through the films, with dramatic increase in permeability as a 
183

184

185

186

187

188

189

190

191

192

193

194

195

196

197

198

199

200

201

202

203

204

205

consequence. When the EC swells in the presence of ethanol the pores will become smaller, and in the extreme cases filled with EC gel. As such, the permeability of the films with a high HPC content is expected to decrease with increasing ethanol concentration in the dissolution medium.

\subsection{Dynamic mechanic analysis}

In order to test the hypothesis that EC swells in ethanol containing dissolution medium, EC film samples were subjected to DMA during submersion in dissolution media with varying ethanol content. The length change, the elastic modulus, $G^{\prime}$, and the loss factor, $\tan (\delta)$, of the samples were recorded during the analyses. In Fig. 3 the percent length change is plotted versus time after submersion for different concentrations of ethanol in the dissolution medium. The film samples expanded more with increasing concentration of ethanol. The effect was rather small for samples exposed to dissolution medium with 0 and $5 \% \mathrm{v} / \mathrm{v}$ ethanol, but more significant for $20 \% \mathrm{v} / \mathrm{v}$ ethanol. For films swollen in dissolution medium containing $40 \% \mathrm{v} / \mathrm{v}$ ethanol the samples displayed a quick and accelerating length expansion up to about $20 \%$ (result not shown), at which point the analyses were terminated due to the instrumental expansion limit. The elastic modulus of the film samples was relatively unaffected by the addition of dissolution medium for ethanol concentrations in the range 0 to $20 \% \mathrm{v} / \mathrm{v}$. However, for the films exposed to the dissolution medium containing $40 \% \mathrm{v} / \mathrm{v}$ ethanol $G^{\prime}$ decreased dramatically even before reaching the expansion limit of the instrument. Further decrease of $G$ ' would be expected if the measurements could have been continued.

The large decrease in $G^{\prime}$ clearly indicates that the samples undergo a transition from a solid to a gelled state in the presence of $40 \% \mathrm{v} / \mathrm{v}$ ethanol. Thus, the dramatic change in sample length 
206 is most likely a combination of swelling of the film and irreversible strain under the small 207 force applied in the DMA.

208 In Fig. 4 the $\tan (\delta)$ values for EC films in dissolution media with different ethanol 209 concentrations are shown. The $\tan (\delta)$ values are equilibrium values for samples exposed to 210 dissolution media with ethanol concentration ranging from 0 to $20 \% \mathrm{v} / \mathrm{v}$. For the films 211 exposed to the dissolution media with $40 \% \mathrm{v} / \mathrm{v}$ ethanol, the reported $\tan (\delta)$ value is acquired 212 from the last measurable values before reaching the instrumental expansion limit. It is seen 213 that the loss factor is small for low concentrations of ethanol, increasing slightly as the 214 ethanol concentration increases. However, for higher ethanol concentrations, the increment is 215 large. The loss factor correlates to the elastic and viscous, G', modulus as (Craig and 216 Johnson, 1995):

$$
\tan (\delta)=\frac{G^{\prime \prime}}{G^{\prime}}
$$

218 As such $\tan (\delta)$ can be regarded as a measurement of how much of a viscous liquid character a material has, as compared to an elastic solid. An increase in $\tan (\delta)$ is equivalent with that a sample dissipates more of the applied energy of deformation as frictional heat, rather than 221 storing the energy as in purely elastic deformation. From the increase in $\tan (\delta)$ with increasing 222 ethanol concentration in the dissolution medium, it can be concluded that the presence of 223 ethanol increases the mobility of the EC polymer chains, causing the samples to dissipate more of the applied deformation energy as heat. The increase of $\tan (\delta)$ with increasing

225 concentration of alcohol is coherent with the increase in sample length, discussed above. 
To investigate if any difference could be detected in the structure of films exposed to

229 dissolution media with varying ethanol content, film samples composed purely of EC and 230 containing $35 \%$ w/w HPC were submerged in dissolution media with different ethanol

231 concentrations for two days. The samples were subsequently dried and analysed using SEM.

232 If the EC was unaffected by the dissolution medium, pure EC films would be unaffected by

233 the treatment and no change in structure should be detected. For the analysed EC-HPC films

234 the HPC should dissolve, leaving a porous network. As for pure EC films, the structure should 235 not be altered by the treatment if EC was not affected by the dissolution medium. However, if 236 the EC swelled in the dissolution medium, altered structures would be expected both for pure 237 EC films and for EC-HPC films.

238 As seen in Fig. 5 A-D, the structure of pure EC films is clearly affected by the ethanol 239 concentration in the dissolution medium. The films that were exposed to dissolution medium 240 containing 20 and $40 \% \mathrm{v} / \mathrm{v}$ ethanol exhibit a different surface than films exposed to 241 dissolution medium with less ethanol, probably due to swelling and subsequent drying. For 242 HPC containing films it is hard to draw any certain conclusions due to the inherent 243 heterogeneity of the films (Fig $5 \mathrm{E}-\mathrm{H})$. However, there is some resemblance between the pure 244 EC film and the HPC containing film submerged in dissolution medium containing $40 \% \mathrm{v} / \mathrm{v}$ 245 ethanol. The results from the SEM analysis support the hypothesis that the performance of 246 EC-HPC films in ethanol containing dissolution medium is influenced by the ethanol 247 concentration through the swelling, and at sufficiently high ethanol concentrations the gelling, 248 of EC.

\section{Conclusion}


In this study it was shown that the water permeability of EC-HPC films for controlled drug

252 delivery was influenced by the concentration of ethanol in the dissolution medium. Ethanol 253 increased the water permeability for no and low amount of HPC in the films, but reduced the 254 permeability at higher HPC content. The effects on the permeability can be explained by that 255 the EC swells in the presence of ethanol, leading to an increased diffusion through the EC in 256 the films, but more importantly decreasing the size of the pores left by the dissolved HPC. 257 This explanation is supported by results from DMA and SEM analysis. The findings are 258 interesting and of great relevance, as the effect of ethanol on controlled release formulations is 259 a current concern expressed by regulatory authorities. The results in this study indicate that 260 the performance of EC-HPC films in controlled delivery applications is at risk with regard to 261 co-ingestion with ethanol. The results here presented mainly showed on a decrease in water 262 permeability. However, given that in most formulations there will be an osmotic pressure 263 difference over the films and that drug molecules are considerably larger than water 264 molecules; our results should not be seen as a proof that dose dumping will not occur. 265 Interesting further studies would be to investigate how the concentration of ethanol in the 266 dissolution medium affects the performance of coated pellets and tablets with different 267 osmotic pressure.

\section{Acknowledgements}

270 This project is part of the VINN Excellence Centre SuMo Biomaterials (Supermolecular

271 Biomaterials - Structure dynamics and properties). The financial support from the Centre is 272 gratefully acknowledged. Further financial support was acquired from the Swedish Research 273 Council and from Chalmers Bioscience Program, Chalmers University of Technology. 
275

276

277 


\section{References}

279 Craig, D.Q.M., Johnson, F.A., 1995. Pharmaceutical applications of dynamic mechanical 280 thermal analysis. Thermochim. Acta 248, 97-115.

281 Donbrow, M., Samuelov, Y., 1980. Zero order drug delivery from double-layered porous films: release rate profiles from ethyl cellulose, hydroxypropyl cellulose and polyethylene glycol mixtures. J. Pharm. Pharmacol. 32, 463-470.

Dow Cellulosics,

2005.

ETHOCEL

Technical

Handbook, http://www.dow.com/dowexcipients/resources/product/ethocel.htm (Available 2010-0322).

Edrud, S., Petersson, M., Stading, M., 2003. DMA Analysis of Biopolymer Film Swelling. Trans. Nordic Rheol. Soc. 11, 155-156.

Fadda, H.M., Mohamed, M.A., Basit, A.W., 2008. Impairment of the in vitro drug release behaviour of oral modified release preparations in the presence of alcohol. Int. J. Pharm. $360,171-176$.

FDA 2005

FDA

ALERT [7/2005]:

Alcohol-Palladone Interaction, http://www.fda.gov/Drugs/DrugSafety/PostmarketDrugSafetyInformationforPatientsand Providers/ucm129288.htm (Available 2010-03-08).

Hjartstam, J., Hjertberg, T., 1998. Swelling of pellets coated with a composite film containing ethyl cellulose and hydroxypropyl methyl cellulose. Int. J. Pharm. 161, 23-28.

Hjartstam, J., Hjertberg, T., 1999. Studies of the water permeability and mechanical properties of a film made of an ethyl cellulose-ethanol-water ternary mixture. J. Appl. Polym. Sci. 74, 2056-2062.

Hyppoelae, R., Husson, I., Sundholm, F., 1996. Evaluation of physical properties of plasticized ethyl cellulose films cast from ethanol solution. Part I. Int. J. Pharm. 133, 161-170. 
Levina, M., Vuong, H., Rajabi-Siahboomi, A.R., 2007. The Influence of Hydro-Alcoholic Media on Hypromellose Matrix Systems. Drug Dev. Ind. Pharm. 33, 1125-1134.

Marucci, M., Hjaertstam, J., Ragnarsson, G., Iselau, F., Axelsson, A., 2009. Coated formulations: New insights into the release mechanism and changes in the film properties with a novel release cell. J. Controlled Release 136, 206-212.

Masaro, L., Zhu, X.X., 1999. Physical models of diffusion for polymer solutions, gels and solids. Prog. Polym. Sci. 24, 731-775.

Meyer, R.J., Hussain, A.S., 2005. FDA's ACPS Meeting, October 2005. Awareness topic: Mitigating the Risks of Ethanol - Induced Dose Dumping from Oral Sustained / Controlled Release Dosage Forms., http://www.fda.gov/ohrms/dockets/ac/05/briefing/2005-4187B1_01_08-AlcoholInduced.pdf (Available 2010-08-05).

Rowe, R.C., Sheskey, P.J., Quinn, M.E., Editors, 2009. Handbook of Pharmaceutical Excipients, Sixth Edition.

Sakellariou, P., Rowe, R.C., 1995. Interactions in cellulose derivative films for oral drug delivery. Prog. Polym. Sci. 20, 889-942.

Sakellariou, P., Rowe, R.C., White, E.F.T., 1986. Polymer/polymer interaction in blends of ethyl cellulose with both cellulose derivatives and polyethylene glycol 6000. Int. J. Pharm. 34, 93-103.

Sakellariou, P., Rowe, R.C., White, E.F.T., 1988. A study of the leaching/retention of watersoluble polymers in blends with ethyl cellulose using torsional braid analysis. J. Controlled Release 7, 147-157.

Shah, N.B., Sheth, B.B., 1972. Method for study of timed-release films. J. Pharm. Sci. 61, $412-416$ 
327 Thombre, A.G., DeNoto, A.R., Falkner, F.C., Lazar, J.D., 1994. In vitro/in vivo correlations 328 of sustained-release coated multiparticulate formulations of doxazosin. Int. J. Pharm. $111,181-189$.

330 


\section{Figure legends}

333 Fig. 1. Exemplifying plot of the volume of water having diffused across the film, here for a 334 sample with $35 \%$ HPC and a thickness of $86 \mu \mathrm{m}$ in dissolution medium with $5 \%$ ethanol.

336 Fig. 2. Plot of the water permeability, normalized versus film thickness, for EC films with varying HPC content, in dissolution media with the following ethanol concentrations ( $\mathbf{\square}) 0$,

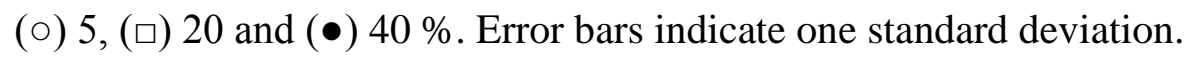

Fig. 3 The percent length change over time for EC films during dynamic mechanic analysis in dissolution media with different ethanol concentration. Dashed lines indicate $\min / \max , \mathrm{n}=2$, where not visible the deviations are too small to be displayed.

344 Fig. 4. The loss factor of EC films in dissolution media with different ethanol concentration, 345 detected using DMA. The values are equilibrium values for ethanol concentrations ranging 346 from 0 to $20 \%$ and the last value before reaching the expansion limit of the instrument for 40 $347 \%$ ethanol. Insert is magnification of the region with ethanol concentrations of 0-20\% Error 348 bars indicate $\min / \max , \mathrm{n}=2$.

Fig. 5. SEM images of pure EC films (A-D) and films containing $35 \% \mathrm{HPC}(\mathrm{E}-\mathrm{H})$ after being 351 submerged in dissolution media with different ethanol concentrations (A, E =0\%; $352 \mathrm{~B}, \mathrm{~F}=5 \% ; \mathrm{C}, \mathrm{G}=20 \%$ and $\mathrm{D}, \mathrm{H}=40 \%$ ) for two days. Scale bar is $20 \mu \mathrm{m}$. 
356 Figure 1.

357

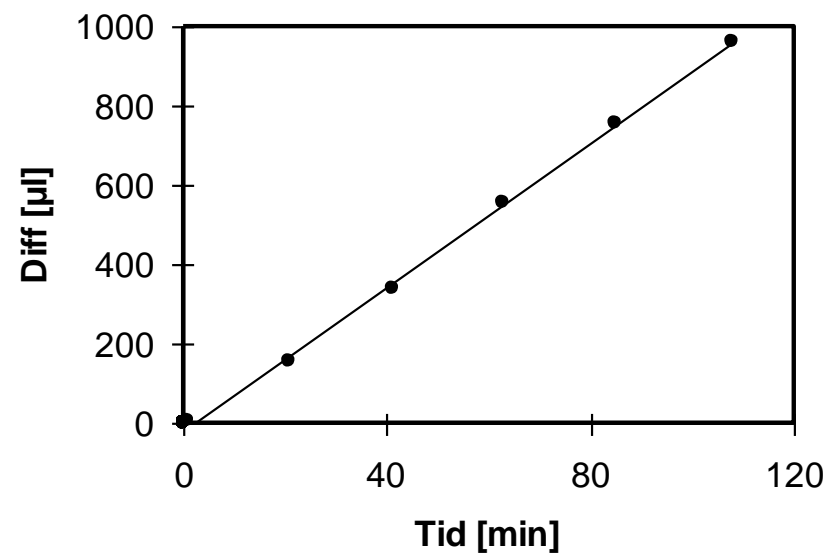

358

359 
360

361

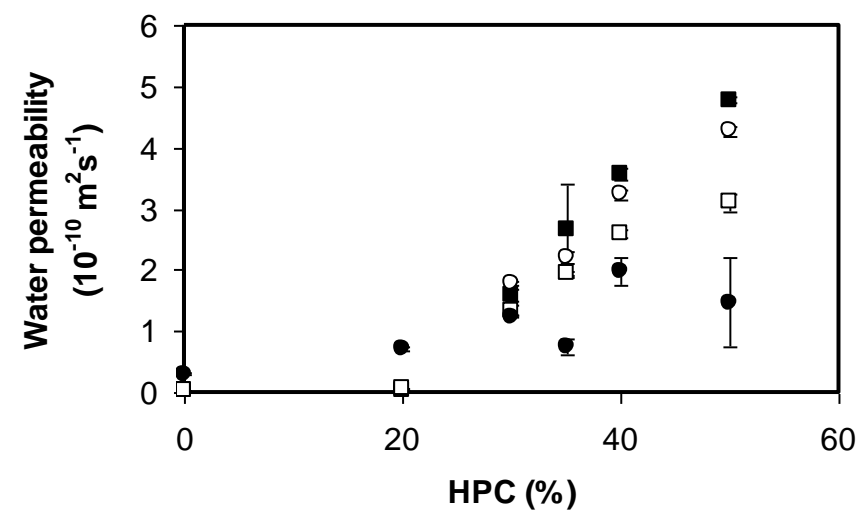

Figure 2.

363 
364

365

366

367

368

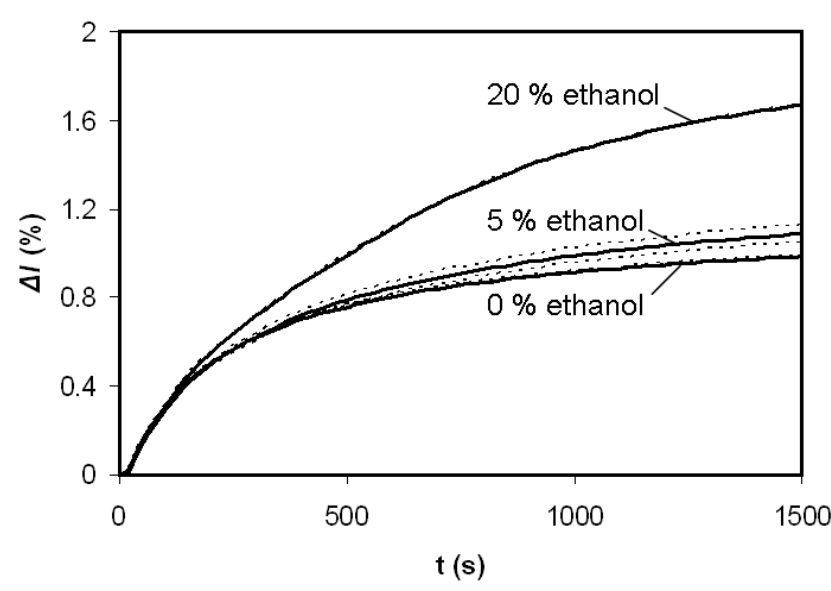


Figure 4.

370

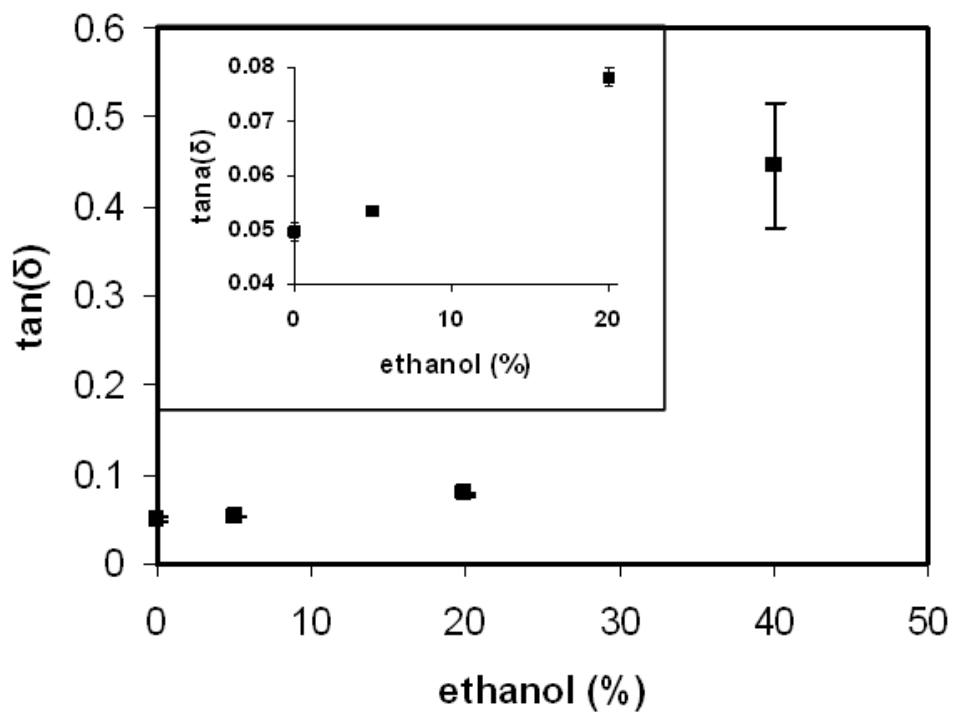

371

372

373 
374

375 Figure 5.

376

377
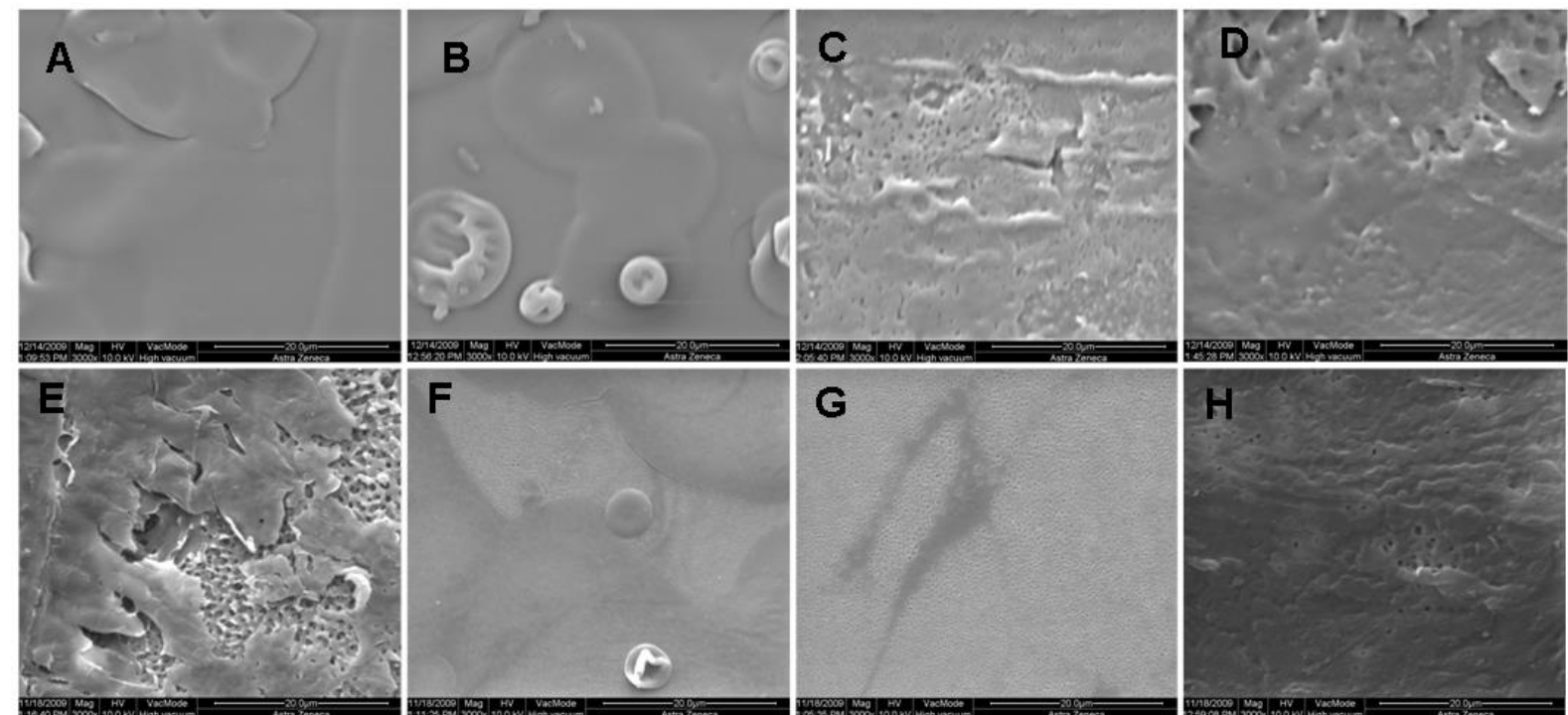

$F$

G

H

378 
380 Table 1. Process parameters used in the preparation of films.

381

\begin{tabular}{cc}
\hline Process parameter & value \\
\hline Inlet air temperature & $72{ }^{\circ} \mathrm{C}$ \\
Outlet air temperature & $45-47.5^{\circ} \mathrm{C}$ \\
Fluidizing air flow rate & $40 \mathrm{Nm}^{3} / \mathrm{h}$ \\
Atomizing air pressure & $2.0 \mathrm{bar}$ \\
Spraying rate & $10 \mathrm{~g} / \mathrm{min}$ \\
\hline
\end{tabular}

382

383

384 
386 Table 2. Water permeability normalized versus film thickness $\left(10^{-12} \mathrm{~m}^{2} \mathrm{~s}^{-1}\right)$ for EC films with 387 varying HPC content, in dissolution media with different ethanol concentrations. One 388 standard deviation within parentheses, $\mathrm{n}=2-5$.

\begin{tabular}{ccccc}
\hline HPC (\%) & 0\% EtOH & 5\% EtOH & $\mathbf{2 0 \%}$ EtOH & $\mathbf{4 0 \%}$ EtOH \\
\hline 0 & $2.3(0.27)$ & $2.40(0.04)$ & $3.9(0.18)$ & $30(1.3)$ \\
20 & $3.4(0.34)$ & $3.61(0.05)$ & $7(1.0)$ & $70(3.4)$ \\
30 & $158(9.9)$ & $177(3.1)$ & $134(8.7)$ & $124(2.0)$ \\
35 & $270(73)$ & $221(9.8)$ & $193(3.7)$ & $70(13)$ \\
40 & $356(9.0)$ & $324(8.1)$ & $260(5.6)$ & $200(22)$ \\
50 & $478(5.0)$ & $427(7.1)$ & $310(15)$ & $150(74)$ \\
\hline
\end{tabular}

389

390

391

392 